\title{
A model study of Abrahamsenbreen, a surging glacier in northern Spitsbergen
}

\author{
J. Oerlemans ${ }^{1}$ and W. J. J. van Pelt ${ }^{2}$ \\ ${ }^{1}$ Institute for Marine and Atmospheric Research Utrecht, Utrecht, the Netherlands \\ ${ }^{2}$ Norsk Polarinstitutt, Troms $\varnothing$, Norway \\ Correspondence to: J. Oerlemans (j.oerlemans@uu.nl)
}

Received: 30 September 2014 - Published in The Cryosphere Discuss.: 7 November 2014 Revised: 9 March 2015 - Accepted: 2 April 2015 - Published: 27 April 2015

\begin{abstract}
The climate sensitivity of Abrahamsenbreen, a $20 \mathrm{~km}$ long surge-type glacier in northern Spitsbergen, is studied with a simple glacier model. A scheme to describe the surges is included, which makes it possible to account for the effect of surges on the total mass budget of the glacier. A climate reconstruction back to AD 1300, based on icecore data from Lomonosovfonna and climate records from Longyearbyen, is used to drive the model. The model is calibrated by requesting that it produce the correct Little Ice Age maximum glacier length and simulate the observed magnitude of the 1978 surge.

Abrahamsenbreen is strongly out of balance with the current climate. If climatic conditions remain as they were for the period 1989-2010, the glacier will ultimately shrink to a length of about $4 \mathrm{~km}$ (but this will take hundreds of years). For a climate change scenario involving a 2 m year $^{-1}$ rise of the equilibrium line from now onwards, we predict that in the year 2100 Abrahamsenbreen will be about $12 \mathrm{~km}$ long.

The main effect of a surge is to lower the mean surface elevation and thereby to increase the ablation area, causing a negative perturbation of the mass budget. We found that the occurrence of surges leads to a faster retreat of the glacier in a warming climate.

Because of the very small bed slope, Abrahamsenbreen is sensitive to small perturbations in the equilibrium-line altitude. If the equilibrium line were lowered by only $160 \mathrm{~m}$, the glacier would steadily grow into Woodfjorddalen until, after 2000 years, it would reach Woodfjord and calving would slow down the advance.

The bed topography of Abrahamsenbreen is not known and was therefore inferred from the slope and length of the glacier. The value of the plasticity parameter needed to do
\end{abstract}

this was varied by +20 and $-20 \%$. After recalibration the same climate change experiments were performed, showing that a thinner glacier (higher bedrock in this case) in a warming climate retreats somewhat faster.

\section{Introduction}

Abrahamsenbreen is a valley glacier in the north-western part of Svalbard $\left(79.10^{\circ} \mathrm{N}, 14.25^{\circ} \mathrm{E}\right)$, originating at the ice field Holtedahlfonna (for more topographic information, see the interactive map: http://www.npolar.no/en/services/maps/). It is about $20 \mathrm{~km}$ long and flows in a north-easterly direction (Fig. 1). The glacier snout terminates on land and is only a few tens of ma.s.l. (above mean sea level). The highest regions in the accumulation area are about $900 \mathrm{~m}$ a.s.l. A large part of the accumulation area is rather flat with an altitude ranging between 600 and $750 \mathrm{~m}$ a.s.1. According to Hagen et al. (1993), the equilibrium-line altitude is around $600 \mathrm{~m}$. The glacial river runs through the very flat Woodfjorddalen over a distance of about $15 \mathrm{~km}$ before it enters the Woodfjord.

The glacial history of northern Spitsbergen is only broadly known (Svendsen and Mangerud, 1997; Forman et al., 2004; Salvigsen and Høgvard, 2005). There is abundant evidence that the fjord areas were deglaciated by $10 \mathrm{kyr}$ BP (Before Present) and that, during most of the Holocene, glaciers were less extensive than they are today. Abrahamsenbreen most likely reached its maximum Holocene extent during the Little Ice Age (LIA), in line with the evidence for many large glaciers in western and southern Spitsbergen (Hagen et al., 1993). One of the goals of this paper is to see whether this is in agreement with palaeoclimatic information derived from 


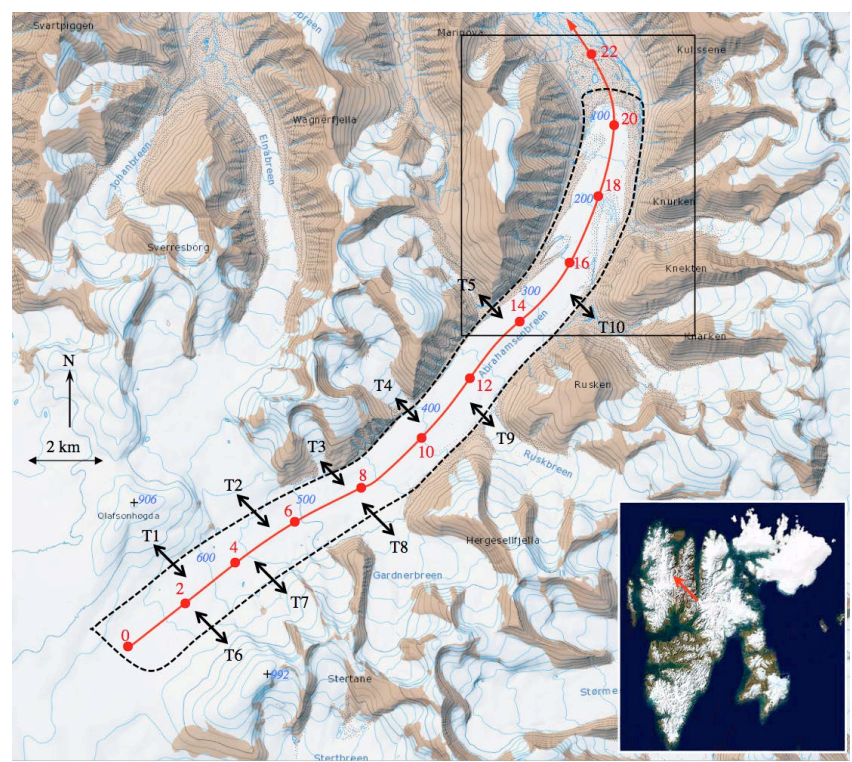

Figure 1. Map of Abrahamsenbreen in northern Spitsbergen (inset), originating from the ice field Holtedahlfonna (lower left corner of the map). The red line shows the flow line along which the length is defined; numbers in red indicate distance from the glacier head in kilometres. Basins and tributary glaciers delivering mass to the main stream are numbered T1-T5 (left) and T6-T5 (right). Isohypses on the glacier in metres above sea level are shown in blue. Glacier stand in 1990 , i.e. after the 1978 surge. Note that looped moraines are actually shown on the map. The rectangle in the upper part refers to the area covered by the aerial photograph of Fig. 2. Map is courtesy of the Norwegian Polar Institute; Landsat image is courtesy of NASA.

the Lomonosovfonna ice cores (Pohjola et al., 2002; Divine et al., 2011) and the meteorological record of Longyearbyen.

Abrahamsenbreen is a surging glacier. It is well known for its fine set of looped moraines (Fig. 2) that were formed during and following the surge that took place around 1978 (Hagen et al., 1993). The duration of the 1978 surge and the frequency with which surges occur is not known. However, it is likely that the surge characteristics of Abrahamsenbreen are similar to those of other gently sloping glaciers in Svalbard. These surges are of a less vigorous type than observed on alpine glaciers like Variegated Glacier (Kamb et al., 1985), Medvezhiy Glacier (Osipova and Tsvetkov, 1991) or North Gasherbrum Glacier (Mayer et al., 2011). Surge characteristics of Svalbard glaciers vary considerably, but the common element is a relatively long surging phase which lasts for several years (Dowdeswell et al., 1991; Melvold and Hagen, 1998; Sund et al., 2009; Dunse et al., 2012). A "normal surge" is an event in which enhanced ice flow transports ice from higher regions to lower regions within a relatively short time, in the end leading to a marked advance of the glacier front. However, in a study of 50 glaciers, Sund et al. (2009) have also documented glacier surges in which the enhanced motion stops before the stage of an advancing front

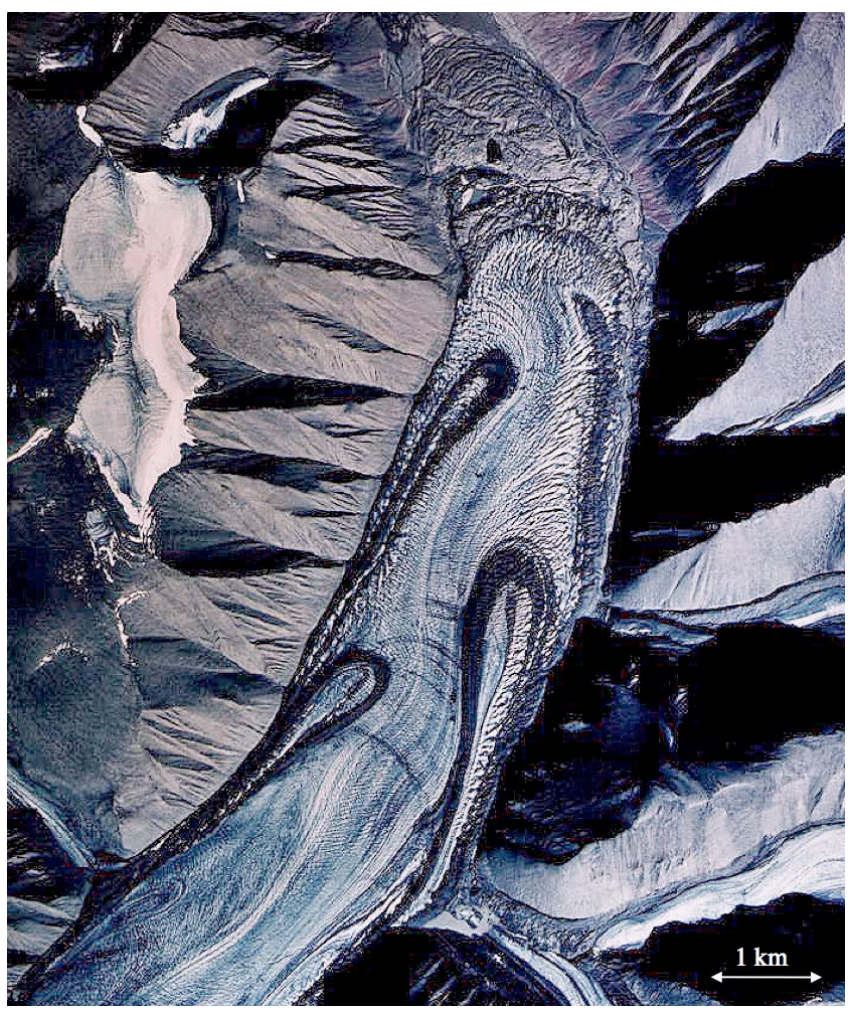

Figure 2. Moraine loops on the lower part of Abrahamsenbreen, formed by rapid displacement of terminal moraines from tributary glaciers during the surge of 1978 (aerial photograph S903134 1990; ${ }^{\circledR}$ Norsk Polarinstitutt).

is reached. The effect of the surge then only implies a thinning of the accumulation region and a thickening of the ablation region. In the case of Abrahamsenbreen there is no doubt that the 1978 surge was a full surge, during which the glacier front advanced by at least $2 \mathrm{~km}$.

After a surge, a glacier will be subject to a negative net surface mass balance, because the mean surface elevation is lower than before the surge. However, because the ice flow becomes (almost) stagnant, after some time the accumulation area will thicken. This implies an increasing surface elevation, less melt in summer and consequently the transition to a stage in which the surface steepens and the glacier volume increases until a new surge is initiated. It is not a priori clear at which point in the cycle Abrahamsenbreen actually is. According to the map of the equilibrium-line altitude over Svalbard provided in Hagen et al. (1993), $E \approx 600 \mathrm{~m}$ in the region of Abrahamsenbreen. For the parameterized glacier geometry used in this study (discussed in Sect. 3), this would imply that the glacier currently has a net balance that is slightly negative. This is in agreement with the study of Nuth et al. (2010), who derived a net balance of $-0.67 \pm 0.14$ mear $^{-1}$ for the period 1966-2005. It should be noted that the surge took place within this period. 
There is no general consensus about the mechanism that causes glaciers in Svalbard to surge (Murray et al., 2003). These glaciers flow over soft sediments, and the duration of surges is significantly longer than for glaciers in steeper alpine terrain, which are at least partly hard-bedded. Thermal regulation has been put forward as a likely mechanism, in which the switch from frozen to warm bed conditions plays a central role (e.g. Fowler et al., 2001). However, direct evidence for this theory does not exist. Oerlemans (2013) has suggested that the steady accumulation of dissipative meltwater in the accumulation zone plays an important role. In recent years geometric changes caused by surging have been documented extensively (e.g. Sund et al., 2009), but this has not yet resulted in a major step forward in our understanding.

Since so many glaciers on Svalbard are of the surging type, the question of to what extent surges interfere with the longer-term response of glaciers to climate change has arisen (Hagen et al., 2005; Paasche, 2010). This question is of importance with respect to the climatic interpretation of historical glacier fluctuations and also needs to be considered when making projections of glacier behaviour for scenarios of global warming. In the simple glacier model used in this study, surges are imposed and their effect on the mass budget is then implicitly dealt with. By comparing model experiments with and without the surging mechanism, the potential role of surges in the evolution of Abrahamsenbreen is evaluated.

In this study the climate sensitivity of Abrahamsenbreen is studied with a simple glacier model. A so-called minimal glacier model is used (Oerlemans, 2011), in which the ice mechanics are strongly parameterized and the focus is on the total mass budget of the glacier. In fact, the ice mechanics are reduced to a relationship between the mean ice thickness, glacier length and mean bed slope. The surge cycle is then imposed by making the proportionality factor between length and thickness a prescribed function of time.

We are aware of the limitations of such a model. It does not give insight into why surges occur and what determines the length of the surge cycle. However, since the mass budget of a (non-calving) glacier is mainly determined by the mean surface elevation relative to the equilibrium-line altitude, the details of the surface topography matter less. Therefore, useful information about the climate sensitivity of a glacier can be obtained even without the calculation of the spatially distributed fields of surface topography and ice velocity.

Hardly any measurements have been carried out on Abrahamsenbreen, making the modelling of this glacier a real challenge.

The available data consist of (references to these data sources are given later in this paper)

- topographic maps from 1966 and 2002

- aerial photographs from 1969 and 1990
- a high-resolution satellite image (ASTER) acquired on 26 June 2001

- mass-balance observations on a nearby glacier (Kongsvegen, $25 \mathrm{~km}$ away)

- a map of the estimated equilibrium-line altitude over Svalbard

- a map of annual precipitation over Svalbard

- geomorphological information about the late Holocene history of Abrahamsenbreen.

In this paper we use these data to constrain and calibrate the model in the best possible way. We consider this exercise to be useful, because for more than $99 \%$ of all glaciers in the world no more information is available than maps, satellite images and photographs.

\section{Modelling strategy and geometric input data}

The geometry of the main stream of Abrahamsenbreen is simple with a very smooth surface profile along the flow line, indicating that the bed is also gently sloping. Major ramps or overdeepenings are likely absent, since they would certainly be reflected in features at the glacier surface (e.g. Raymond and Gudmundsson, 2005). Such a regular geometry is a prerequisite for the use of a minimal glacier model, which requires a small set of input parameters and can be calibrated easily with the limited data available. In a minimal glacier model the state variables are glacier length and mean ice thickness.

Before describing this model we will first summarize some of the information about the lower part of the glacier that is evident from the two aerial photographs (from 1969 and 1990), two topographic maps (1966 and 2002) and a satellite image (ASTER, 26 June 2001).

Terminal moraines from the tributary glaciers T4, T5, T9 and T10 (Fig. 1) are schematically mapped for 3 years (Fig. 3). The distance between the locations of the moraines in different years was calculated by projecting the moraine tips on the central flow line and measuring the displacement. For the displacement between 1990 and 1969 we found respectively 4.5 and $4.7 \mathrm{~km}$ for $\mathrm{M} 1$ and $\mathrm{M} 3$ and 5.9 and $6.3 \mathrm{~km}$ for M2 and M4. Using the mean values of the paired moraines (left and right of the glacier), average corresponding ice velocities would be 219 myear $^{-1}$ for the lower region of the glacier and about 290 m year $^{-1}$ for the middle part. The displacement between 2001 and 1990 is small, with corresponding velocities of 9 and 23 myear $^{-1}$. If we think of the ice velocity as composed of a background part and a surge part and we assume that the background part has been constant, it follows that the displacement of surface ice due to the surge would be $4.4 \mathrm{~km}$ for the lower part and 


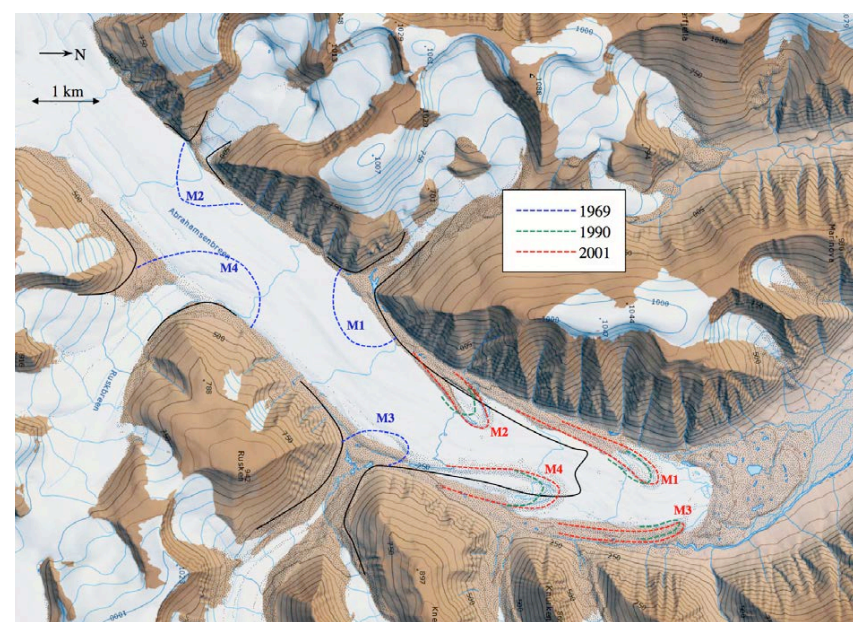

Figure 3. A close-up of the lower part of Abrahamsenbreen. The black solid lines indicate the glacier margin in 1966 (topographic map from the Norsk Polarinstitutt). The moraine loops are numbered M1-M4, and their migration has been visualized by using dashed lines of different colour to indicate the approximate positions in different years. The 1969 and 1990 locations have been taken from aerial photographs (S691493 and S903134; ${ }^{\circ}$ Norsk Polarinstitutt), the 2001 locations from an ASTER image (26 June 2001; NASA). Note that the map has been rotated over $90^{\circ}$ with respect to Figs. 1 and 2.

$5.6 \mathrm{~km}$ for the middle part. It is not straightforward to convert these data into a total advance of the glacier front during the surge. Comparing the glacier outlines on the maps suggests a frontal advance of $1.8 \mathrm{~km}$. However, the glacier front will have melted back from a more advanced position during the period 1978 (surge) to 2002 (map outline). Judging from the size of the moraine system (Figs. 2 and 3), retreat of the snout could have been at most $1.6 \mathrm{~km}$ during this period. This would imply that the total advance of the front related to the surge is not larger than $3.4 \mathrm{~km}$.

Altitudinal profiles along the central flow line are shown in Fig. 4. The absolute error of the topographic maps in this area is not known, but the profiles appear to be consistent with the occurrence of the surge in 1978. The mean slope of the pre-surge profile (1966) is 0.035 , while that of the postsurge profile (2002) is 0.027 . The mean difference in altitude $(\Delta \bar{h})$ between the profiles is $51 \mathrm{~m}$. It should be noted once more that by the year 2002 part of the glacier snout has retreated. Hence, the mean difference in altitude shortly before and after the surge probably was somewhat larger. The value of $\Delta \bar{h}$ cannot be taken directly as a measure of the change in mean ice thickness $\Delta H_{\mathrm{m}}$, because the mean bed elevation is also different before and after the surge (solely due to the change in glacier length). With the representation of the bed chosen here (discussed shortly) we found $\Delta \bar{b}=13 \mathrm{~m}$. Altogether, we used a value of $\Delta H_{\mathrm{m}}=50 \mathrm{~m}$ to characterize the change related to the surge.

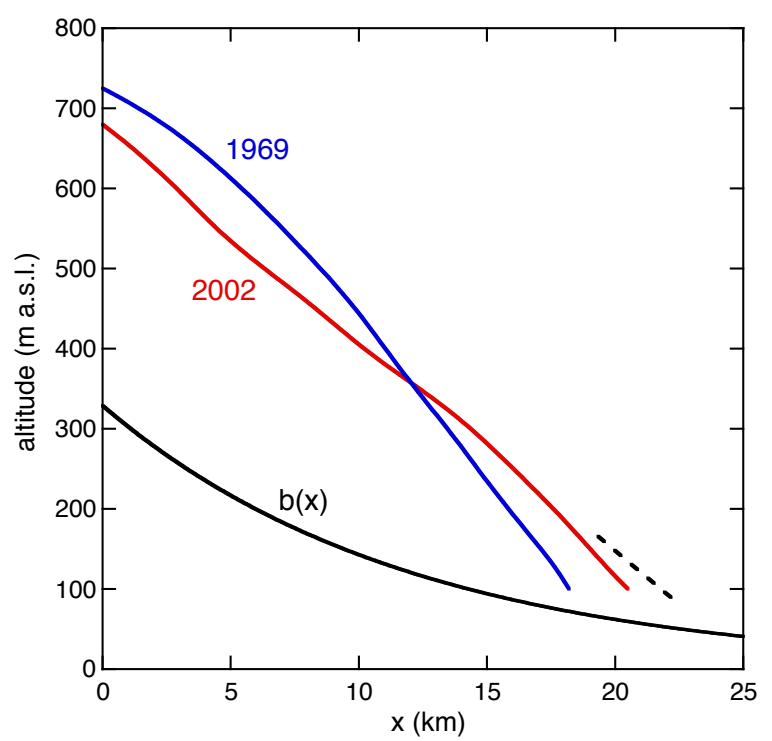

Figure 4. Altitude profiles along the central flow line of Abrahamsenbreen derived from topographic maps. The surge took place around 1978. The dashed line indicates a possible maximum extension of the glacier immediately after the surge. The reference bed profile is shown as $b(x)$.

Since the maps from which the profiles are taken are 36 years apart, the difference in mean surface elevation can also partly be due to a non-zero surface balance rate during this period. Unfortunately, in situ measurements are not available to check this. Nuth et al. (2010) infer a negative mean balance rate for the period 1966-2005 from remote sensing data. However, in their map of elevation changes over north-west Spitsbergen (their Fig. 5), the outlines for Abrahamsenbreen are not identical to those inferred here from the 2002 topographic map. The difference is mainly in the size of the accumulation area (larger in the present study), which had a slightly positive balance rate during the period 1966-2005. In view of this, we have not made any corrections to the value of $\Delta H_{\mathrm{m}}=50 \mathrm{~m}$ as being characteristic for the surge. We also note that with a significantly different (smaller) value, it is impossible to explain the glacier advance during the surge in terms of mass conservation (which implies a direct relation between change in glacier length and change in mean ice thickness).

The geometric set-up of the model is shown in Fig. 1. The main glacier is modelled as a flow band with a constant width of $2000 \mathrm{~m}$. It has its own surface mass budget, which is definitely negative because it is almost entirely in the ablation zone. The main stream is fed by tributary basins and glaciers numbered $\mathrm{T} 1, \ldots, \mathrm{T} 10$. The mass input from these tributaries is parameterized in terms of a schematic geometry and depends on the climatic state. Details on this are described in Sect. 4. We assume that the tributaries have a considerably smaller characteristic response time than the main glacier 
because they are steeper, implying that the net balance of the tributaries is calculated as if they were in a quasi-steady state. This also implies that tributaries having a negative net balance are simply ignored in the total mass budget.

The bed topography is basically unknown. The surface of the glacier is smooth and has a small slope $(\sim 0.03)$, suggesting that a simple formulation of the bed profile is adequate. A bed topography that can be handled well by the minimal glacier model reads

$b(x)=b_{\mathrm{h}} \exp \left(-x / x_{1}\right)$.

Thus the bed elevation drops off exponentially from a value $b_{\mathrm{h}}$ at the highest point of the flow band $(x=0)$ to sea level for large values of $x$ (see Fig. 1). The characteristic length scale at which the bed becomes lower is denoted by $x_{1}$. We also considered using a linear bed profile, but this generates problems for glacier stands that are significantly larger than today (a bed far below sea level, which is unrealistic in this case). Here we chose $x_{1}=12000 \mathrm{~m}$. Admittedly, this value is not more than an educated guess based on the general picture of valleys in northern Spitsbergen that are more deglaciated than the Abrahamsenbreen valley (topographic map: http://www.npolar.no/en/services/maps/). The value for $b_{\mathrm{h}}$ is discussed later.

\section{Glacier model}

The theory of minimum glacier models has been developed in Oerlemans (2011), and the reader is referred to that work for details (freely available from the internet; http://www.staff.science.uu.nl/ oerle102/MM2011-all. pdf). We only give a brief description of the model version used here.

The starting point for the model formulation is the continuity equation:

$$
\frac{\mathrm{d} V}{\mathrm{~d} t}=F+B_{\mathrm{A}}+\sum_{i=1}^{10} B_{i},
$$

where $V$ is the volume of Abrahamsenbreen, $F(<0)$ is the calving flux, $B_{\mathrm{A}}$ is the total surface mass budget of Abrahamsenbreen and the last term represents the mass input from the tributary glaciers as defined in Fig. 1. The glacier length $L$ is measured along the central line on the glacier (Fig. 1). Since here we do not consider states of Abrahamsenbreen where it calves into the Woodfjord, we set $F=0$.

Because the glacier width $w$ is assumed to be constant, the rate of change of ice volume can be written as

$$
\frac{\mathrm{d} V}{\mathrm{~d} t}=w \frac{\mathrm{d}}{\mathrm{d} t}\left(H_{\mathrm{m}} L\right)=w\left(H_{\mathrm{m}} \frac{\mathrm{d} L}{\mathrm{~d} t}+L \frac{\mathrm{d} H_{\mathrm{m}}}{\mathrm{d} t}\right)=B_{\mathrm{tot}},
$$

where $B_{\text {tot }}$ is the right-hand side of Eq. (1), the total mass budget of the glacier.
The mean ice thickness is parameterized as (Oerlemans, 2011)

$H_{\mathrm{m}}=S \frac{\alpha_{\mathrm{m}}}{1+\nu \bar{s}} L^{1 / 2}$,

where $\bar{s}$ is the mean slope of the bed over the glacier length and $\alpha_{\mathrm{m}}$ and $v$ are constants. A "surge function" $S$ has been introduced, which makes it possible to impose a surge cycle. $S$ is prescribed as a function of time. A rapid decrease of $S$ mimics the surge, whereas a steady increase of $S$ represents the quiescent phase during which the glacier thickness steadily increases. The precise form of $S(t)$ will be discussed later.

The parameterization of the mean ice thickness as described by Eq. (4) gives a good fit to results from numerical flow line models. For $\bar{s} \rightarrow 0$ the mean thickness varies with the square root of the glacier length, which is in agreement with the perfectly plastic and Vialov solutions for a glacier/ice cap on a flat bed (Weertman, 1961; Vialov, 1958). The minimal glacier model was used earlier in a study of Hansbreen, southern Spitsbergen (Oerlemans et al., 2011). The bed topography of Hansbreen is known, and it was found that Eq. (4) matches the observed mean thickness for $v=10$ and $\alpha_{\mathrm{m}}=3 \mathrm{~m}^{1 / 2}$. However, Hansbreen is a non-surging tidewater glacier in a different geographical and geological setting; therefore from the very few glaciers with bedrock data we have selected Kongsvegen as a better glacier to estimate the parameter $\alpha_{\mathrm{m}}$. Like Abrahamsenbreen, Kongsvegen is a surging glacier, which is currently in its quiescent phase (Melvold and Hagen, 1998). It is not located far away from Abrahamsenbreen (about $25 \mathrm{~km}$ ). From the bed and surface profiles of Kongsvegen a value of $\alpha_{\mathrm{m}}=2.27 \mathrm{~m}^{1 / 2}$ is found, indicating that basal conditions here allow for a lower resistance than in the case of Hansbreen. We have used the value of $\alpha_{\mathrm{m}}=2.27 \mathrm{~m}^{1 / 2}$ as the best possible estimate for Abrahamsenbreen. However, different values of this parameter will be used later in a sensitivity test.

Using the chain rule for differentiation, the time rate of change of ice thickness can be expressed as

$$
\begin{aligned}
L \frac{\mathrm{d} H_{\mathrm{m}}}{\mathrm{d} t} & =\frac{\alpha_{\mathrm{m}}}{2(1+\nu \bar{s})} S L^{1 / 2} \frac{\mathrm{d} L}{\mathrm{~d} t}-\frac{\alpha_{\mathrm{m}} \nu}{(1+\nu \bar{s})^{2}} S L^{3 / 2} \frac{\partial \bar{s}}{\partial L} \frac{\mathrm{d} L}{\mathrm{~d} t} \\
& +\frac{\alpha_{\mathrm{m}}}{(1+\nu \bar{s})} L^{3 / 2} \frac{\mathrm{d} S}{\mathrm{~d} t} .
\end{aligned}
$$

Combining with Eq. (3) then yields

$$
\begin{aligned}
B_{\mathrm{tot}} & =w\left(\frac{3 \alpha_{\mathrm{m}}}{2(1+\nu \bar{s})} S L^{1 / 2} \frac{\mathrm{d} L}{\mathrm{~d} t}-\frac{\alpha_{\mathrm{m}} \nu}{(1+v \bar{s})^{2}} S L^{3 / 2} \frac{\partial \bar{s}}{\partial L} \frac{\mathrm{d} L}{\mathrm{~d} t}\right. \\
& \left.+\frac{\alpha_{\mathrm{m}}}{(1+v \bar{s})} L^{3 / 2} \frac{\mathrm{d} S}{\mathrm{~d} t}\right) .
\end{aligned}
$$

Here $B_{\text {tot }}$ is the total mass budget, i.e. the right-hand side of Eq. (3). 
The prognostic equation for the length of the glacier can thus be written as

$\frac{\mathrm{d} L}{\mathrm{~d} t}=\frac{B_{\mathrm{tot}}}{w(a+b)}-\frac{c}{(a+b)} \frac{\mathrm{d} S}{\mathrm{~d} t}$,

where

$a=\frac{3}{2} H_{\mathrm{m}} ; b=-\frac{\nu H_{\mathrm{m}} L}{(1+\nu \bar{s})} \frac{\partial \bar{s}}{\partial L} ; c=-\frac{H_{\mathrm{m}} L}{S}$.

From Eq. (7) it is clear that a sufficiently rapid decrease of $S(\mathrm{~d} S / \mathrm{d} t \ll 0)$ leads to a strong increase in $L$ (but not in $V$ ).

For the exponentially decaying bed profile described by Eq. (1) the mean bed slope over the glacier length is easily found to be

$\bar{s}=\frac{b_{\mathrm{h}}\left(1-e^{-L / x_{1}}\right)}{L}$.

The term $\partial \bar{s} / \partial L$, needed in the coefficient $b$ in Eq. (8), is

$\frac{\partial \bar{s}}{\partial L}=-\frac{b_{0}\left(1-e^{-L / x_{1}}\right)}{L^{2}}+\frac{b_{0} x_{1}^{-1} e^{-L / x_{1}}}{L}$.

This concludes the formulation of the glacier model. When $B_{\text {tot }}$ is known, Eq. (7) can be integrated in time with a simple forward time-stepping scheme. The calculation of $B_{\text {tot }}$ is described in the next section.

\section{Formulation of the mass budget}

\subsection{Mass budget of the main glacier}

Mass-balance measurements have been carried on a number of glaciers in Svalbard but not on Abrahamsenbreen. Glaciers with a mass-balance record of at least 10 years, as filed at the World Glacier Monitoring Service, are Midtre Lovénbreen, Kongsvegen, Hansbreen and Austre Brøggerbreen. Long-term mean balance profiles are shown in Fig. 5 . These profiles suggest that a schematic representation of the balance rate can be taken as a linear function of altitude, i.e.

$\dot{b}=\beta(h-E)$,

where $\beta$ is the balance gradient and $E$ is the equilibriumline altitude. Linear regression on the profiles shown in Fig. 5 yields values of $\beta$ ranging from 0.0039 to $0.0053 \mathrm{~m} \mathrm{w}$.e. $\mathrm{m}^{-1}$. The mean value is $0.0045 \mathrm{mw}$.e. $\mathrm{m}^{-1}$, which is used in this study. It is clear from the available observations that a higherorder formulation, e.g. with a quadratic term in $h$, is not meaningful. However, according to Hagen et al. (1993; their Fig. 8), annual precipitation decreases significantly when going in a north-easterly direction from the Holtedahlfonna, implying an increase in the equilibrium-line altitude of about 100-150 m over the length of Abrahamsenbreen (assuming a sensitivity of $E$ with respect to changes in precipitation of

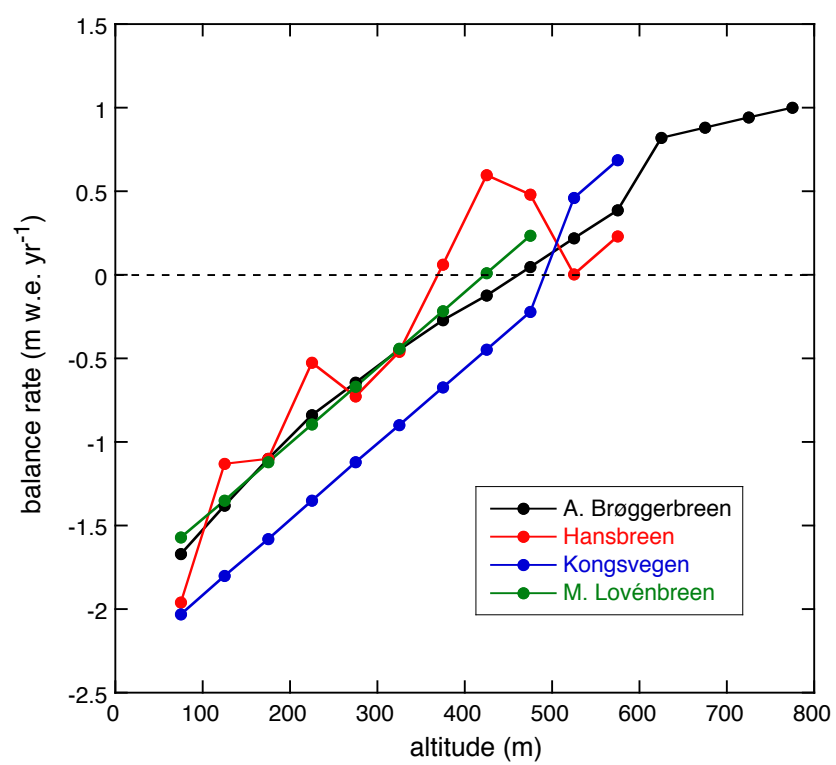

Figure 5. Observed mean balance profiles for Austre Brøggerbreen (1990-2009), Hansbreen (1991-2009), Kongsvegen (2000-2009) and Midtre Lovénbreen (2000-2009). Data are from the World Glacier Monitoring Service (Zurich).

$-2.25 \mathrm{~m}$ per $\%$, see Sect. 6.1). This is taken into account by making $E$ a function of $x$ :

$E=E_{0}+\gamma x$,

where $\gamma$ is the spatial gradient of the equilibrium-line altitude along the flow line of the glacier. From the glacier length and change of $E$ we estimate $\gamma=0.005$.

The total mass gain or loss can now be found by integrating the balance rate over the glacier surface:

$$
\begin{aligned}
B_{\mathrm{s}} & =\beta \int_{0}^{L}\left\{H(x)+b(x)-E_{0}-\gamma x\right\} \mathrm{d} x \\
& =\beta\left(H_{\mathrm{m}}+\bar{b}-E_{0}\right) L-\frac{\beta \gamma}{2} L^{2},
\end{aligned}
$$

where $\bar{b}$ is the mean bed elevation of the glacier. For the exponentially decaying bed profile it is given by

$\bar{b}=\frac{b_{\mathrm{h}}}{L} \int_{0}^{L} e^{-x / x_{1}} \mathrm{~d} x=\frac{x_{1} b_{\mathrm{h}}}{L}\left(1-e^{-L / x_{1}}\right)$.

\subsection{Tributary glaciers}

For the tributary glaciers feeding the main stream, some further analysis is required to arrive at useful estimates of the mass input. Although the tributary glaciers could be modelled in a similar way as the main glacier, we take a somewhat simpler approach in which the surface geometry is fixed. This 
is justified because the tributary glaciers have much larger mean slopes and therefore a weaker altitude-mass-balance feedback.

We assume that a tributary glacier can be described as a basin with a length $L_{y}$ and a width $w(y)=w_{0}+q y$. Here $y$ is a local coordinate running from the lowest part of the basin $(y=0)$ to the highest part of the basin $\left(y=L_{y}\right)$. The surface elevation is taken as $h(y)=h_{0}+s y$, where $s$ is the surface slope. The parameters $q$ and $s$ are constants which are different for the individual basins. The total mass budget $B_{i}$ of basin $i$ is then obtained from

$B_{i}=\int_{0}^{L_{y}} \beta\left(b_{0}+s y-E\right)\left(w_{0}+q y\right) \mathrm{d} y$.

Evaluating the integral yields

$B_{i}=\beta\left[w_{0}\left(b_{0}-E\right) L_{y}+\frac{1}{2}\left\{s w_{0}+\left(b_{0}-E\right) q\right\} L_{y}^{2}+\frac{1}{3} s q L_{y}^{3}\right]$.

The geometric characteristics of the basins have been estimated from the topographic map and are summarized in Table 1 . All basins have a trapezoidal shape, some becoming narrower when going up $(q<0)$ and some wider $(q>0)$. Due to the spatial gradient in $E$ (see Eq. 11) the basins which are located further downstream along the $x$ axis will experience a slightly higher equilibrium-line altitude. This is accounted for by applying a basin-dependent correction (Table 1).

\section{Basic experiments}

For $S=1$ and $E=587 \mathrm{~m}$ the model produces a steady-state glacier with a length of $17.5 \mathrm{~km}$, which is close to the presurge length (we cannot define this precisely). A good match between the calculated and observed (pre-surge) mean surface elevation is obtained with $b_{\mathrm{h}}=323 \mathrm{~m}, \alpha_{\mathrm{m}}=2.27 \mathrm{~m}^{1 / 2}$. The mean ice thickness then is $263 \mathrm{~m}$. We refer to this state as the reference state. The corresponding mass inputs from the tributary basins are given in the last column of Table 1. The net balance of the main glacier stream is $-0.66 \mathrm{~m}$ w.e., and this is then compensated exactly by the mass input from the tributaries. Glaciers, and certainly surging glaciers, are never in steady state. Nevertheless, it is useful to have a steady state as a reference state, because it reveals basic properties of the glacier model. At this point it should be noted that the value of the bed parameter $b_{\mathrm{h}}$ is determined by the value of $\alpha_{\mathrm{m}}$. Although we believe that the value of $\alpha_{\mathrm{m}}$ as discussed in Sect. 3 is a good choice, we will later discuss a few sensitivity tests to show how the value of $\alpha_{\mathrm{m}}$ affects the results.

The next step is to introduce the surge behaviour. The surge function is formulated as

$S(t)=C-S_{\mathrm{a}}\left(t-t_{0}\right) e^{-\left(t-t_{0}\right) / t_{\mathrm{s}}}+S_{\mathrm{q}}\left(t-t_{0}\right)$.
Table 1. Parameter values of the geometric characteristics of the basins that feed the main stream. See Fig. 1 for the location of the basins. The last column shows the mass input (ice volume) to the main glacier corresponding to the reference state described in the next section.

\begin{tabular}{lccccrcc}
\hline Basin & $\begin{array}{c}L_{y} \\
(\mathrm{~m})\end{array}$ & $\begin{array}{c}w_{0} \\
(\mathrm{~m})\end{array}$ & $\begin{array}{c}b_{0} \\
(\mathrm{~m})\end{array}$ & $s$ & $\begin{array}{c}q \\
(\mathrm{~m})\end{array}$ & $\begin{array}{c}E_{\mathrm{b}, \text { corr }} \\
(\mathrm{m})\end{array}$ & $\begin{array}{c}B_{\text {ref }} \\
\left(\mathrm{m}^{3} \text { year }^{-1}\right)\end{array}$ \\
\hline T1 & 2100 & 4200 & 650 & 0.119 & -1.00 & 0 & $8.4 \times 10^{6}$ \\
T2 & 4600 & 2600 & 550 & 0.058 & 0.0 & 15 & $4.9 \times 10^{6}$ \\
T3 & 2100 & 300 & 480 & 0.257 & 0.18 & 25 & $4.4 \times 10^{5}$ \\
T4 & 3400 & 400 & 410 & 0.163 & 0.71 & 44 & $3.9 \times 10^{5}$ \\
T5 & 4100 & 300 & 320 & 0.186 & 0.54 & 65 & $3.1 \times 10^{5}$ \\
T6 & 1800 & 2300 & 650 & 0.147 & -0.65 & 0 & $4.1 \times 10^{6}$ \\
T7 & 2100 & 3500 & 600 & 0.120 & -0.12 & 11 & $4.8 \times 10^{6}$ \\
T8 & 4200 & 1300 & 500 & 0.103 & 0.82 & 25 & $2.9 \times 10^{6}$ \\
T9 & 5800 & 600 & 430 & 0.090 & 0.70 & 55 & $8.6 \times 10^{5}$ \\
T10 & 5600 & 300 & 280 & 0.145 & 0.54 & 77 & $1.9 \times 10^{5}$ \\
\hline
\end{tabular}

The surge starts at $t=t_{0}$ and the surge amplitude $S_{\mathrm{a}}$ determines by how much the thickness of the glacier is reduced. The characteristic timescale of the surge is denoted by $t_{\mathrm{s}}$. The last term in Eq. (16) represents the quiescent phase of the surge cycle, during which the glacier steadily thickens because the mass flux is smaller than the balance flux. The constant $C$ should be chosen in such a way that the long-term mean value of $S(t)$ is close to 1 .

We use $t_{\mathrm{s}}=2.5$ years. This value is based on the observation that most surges of Svalbard glaciers typically last a few years (Sund et al., 2009). The value of $S_{\mathrm{q}}$ is determined by two factors: the rate of mass addition in the accumulation area and the degree to which the glacier motion slows down after the surge. For the present case we have chosen values of $S_{\mathrm{a}}$ and $S_{\mathrm{q}}$ in such a way that (i) the frontal advance related to the surge is reproduced and (ii) the difference in the mean ice thickness before and after the surge is in agreement with the observations (about $50 \mathrm{~m}$; Sect. 2). We thus found $S_{\mathrm{a}}=0.168$ year $^{-1}$ and $S_{\mathrm{q}}=0.002$ year $^{-1}$.

The duration of the surge cycle for Abrahamsenbreen is not known. For most glaciers the duration of the quiescent phase is in the 50-500-year range (e.g. Dowdewell et al., 1991). Because Abrahamsenbreen is a large and rather flat glacier in a relatively dry climate, we have chosen a surge cycle of $\Theta=125$ years. Later we will show sensitivity tests that reveal how the particular choice of $\Theta$ affects the results.

A model simulation in which the surge mechanism is switched on at some point in time (after the glacier has reached the reference state defined above) is shown in Fig. 6. As discussed above, a surge leads to a sudden decrease of the mean ice thickness and associated negative net balance $\left(-0.3 \mathrm{~m} \mathrm{year}^{-1}\right.$ just after the surge). During the quiescent phase the net balance gradually becomes positive and the ice thickness increases, but this is not enough to compensate for the mass loss during and just after the surge. Therefore the glacier length decreases until a new equilibrium is reached 


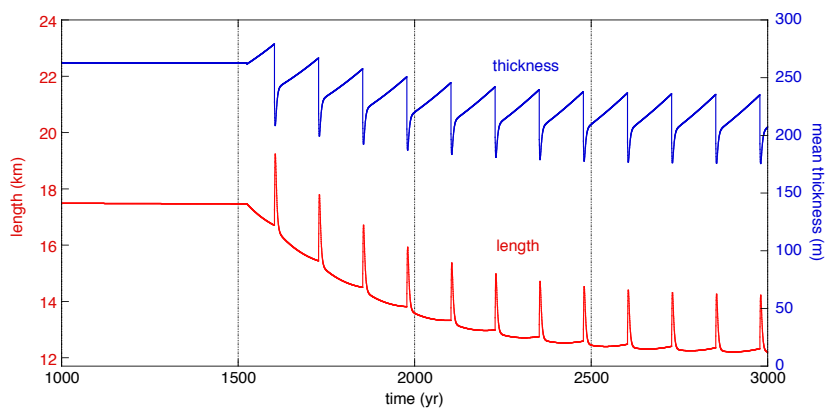

Figure 6. Surge event as imposed to the model by Eq. (16).

after about 1000 years. Thus, the net effect of the surging mechanism is to reduce the long-term glacier length. This is in agreement with earlier studies (Adalgeirsdóttir et al., 2005; Oerlemans, 2011).

\section{Response of Abrahamsenbreen to climate change}

\subsection{Reference simulation}

In this section we describe how a reference simulation, including the surging behaviour, has been obtained. A simulation of the evolution of Abrahamsenbreen during the late Holocene requires a plausible climatic forcing. In the present model climate change is imposed by adjusting the equilibrium-line altitude according to

$E(t)=E_{0}+E^{\prime}(t)$.

The annual perturbation of the equilibrium-line altitude is denoted by $E^{\prime}(t)$ and determined by annual temperature and precipitation anomalies, denoted by $T^{\prime}$ (in $\mathrm{K}$ ) and $P^{\prime}$ (in \%) respectively. $E^{\prime}(t)$ is thus written as

$E^{\prime}(t)=\frac{\partial E}{\partial T} T^{\prime}(t)+\frac{\partial E}{\partial P} P^{\prime}(t)$,

where the sensitivities $\partial E / \partial T$ and $\partial E / \partial P$ are assumed to be constant. Sensitivities have been determined for Nordenskiöldbreen with a detailed energy and mass-balance model (van Pelt et al., 2012; Table 2), and here we use their values:

$\frac{\partial E}{\partial T}=35 \mathrm{mK}^{-1} ; \quad \frac{\partial E}{\partial P}=-2.25 \mathrm{~m} \%{ }^{-1}$.

For many glaciers in a more alpine setting, values of $\partial E / \partial T$ are of the order of $100 \mathrm{~m} \mathrm{~K}^{-1}$ (e.g. Oerlemans, 2011). The value for $\partial E / \partial T$ given in Eq. (19) thus appears as rather small. This is due to the fact that in the high Arctic summer temperature, anomalies which mainly determine the sensitivity are much smaller than annual temperature anomalies. This has been taken into account in the determination of the sensitivities.

The input data to calculate $E^{\prime}$ are taken from van Pelt et al. (2013). In this paper a climate reconstruction back to $\mathrm{AD} 1300$ was made on the basis of ice-core data from Lomonosovfonna as well as climate records from Longyearbyen. For details the reader is referred to Divine et al. (2011) and van Pelt et al. (2013). The temperature and precipitation anomalies, relative to the period 1989-2010, are shown in Fig. 7, and the corresponding history of the equilibrium-line altitude in Fig. 8. The most prominent feature in the reconstructed temperature record is the LIA, lasting from the late 16th century to the end of the 19th century, with long-term temperatures typically $4 \mathrm{~K}$ below the medieval and presentday levels. The reconstruction does not reveal a clear correlation between temperature and precipitation anomalies. The variation of the equilibrium-line altitude is substantial. During the period 1750-1850, the equilibrium line was about $200 \mathrm{~m}$ lower than in medieval times.

The value of $E_{0}$ is optimized in such a way that the simulated maximum glacier length in 1978 corresponds to the observed length. This yields $E_{0}=657 \mathrm{~m}$. Note that $E^{\prime}$ is defined with respect to the period 1989-2010, implying that its mean value over the period $1300-2010$ is not 0 . In the climate reconstruction used here, the value of $E$ during the period 1989-2010 was $76 \mathrm{~m}$ larger than the long-term mean since AD 1300.

The simulated glacier length (Fig. 8) appears to be in good agreement with geological evidence (distribution of moraines, strand lines and floodplains). There is general agreement that Abrahamsenbreen reached a Holocene maximum extent during the LIA, like most glaciers in northern Spitsbergen (e.g. Forman et al., 2004; Salvigsen and Høgvard, 2005; Humlum et al., 2005). According to our model, Abrahamsenbreen would have had a length of about $5 \mathrm{~km}$ in medieval times and started to grow in the 16th century until it reached LIA size (between 18 and $22 \mathrm{~km}$ ) in the second half of the 19th century. For the calculation shown in Fig. 8, the value of $E$ has been kept constant to the 1989-2010 value for the period after 2010 . This clearly implies steady retreat, but the timescale at which this happens is large. This is an implication of the very small bed slope and the related strong altitude-mass-balance feedback (Oerlemans, 2011).

Figure 9 shows the mass inputs (in $\mathrm{m}^{3}$ of ice per year) of the tributary basins and glaciers corresponding to the simulation shown in Fig. 8. Although the inputs are highly correlated, there are large differences in the absolute changes of mass input through time. The input from tributary glaciers $\mathrm{T} 4, \mathrm{~T} 5$ and $\mathrm{T} 10$ is sometimes 0 . For T9 this happens just a few times. The other basins always deliver some mass to the main glacier, but the amounts can halve or double during high or low values of $E^{\prime}$.

We refer to the simulation just described as the reference simulation. The model has been tuned in the best possible way given the limited amount of observations. There appears to be no evident discrepancy between the simulated glacier evolution and the geological evidence. 


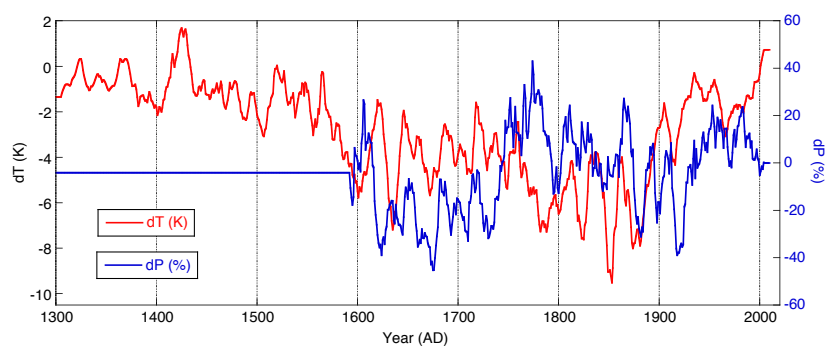

Figure 7. Climate history used to simulate the evolution of Abrahamsenbreen during the late Holocene (Van Pelt et al., 2013). Shown are anomalies of the annual mean temperature and the annual precipitation.

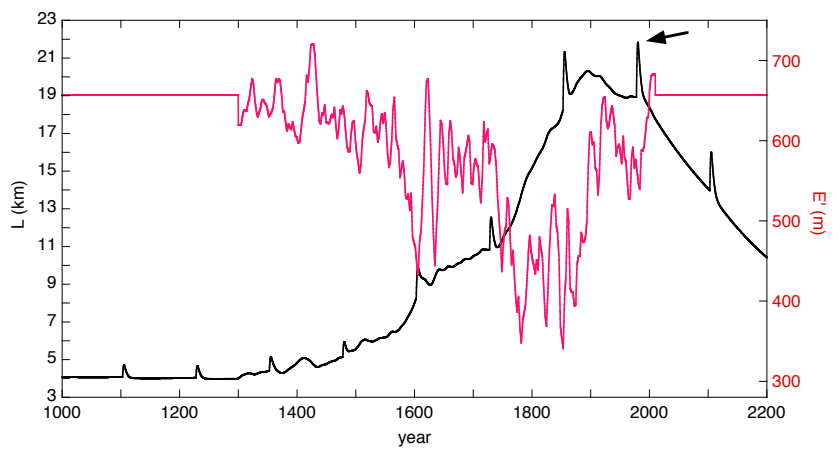

Figure 8. Glacier length (in black, scale at left) and equilibrium-line altitude (in red, scale at right) from the simulation of Abrahamsenbreen. The arrow indicates the 1978 surge of the glacier.

\subsection{The effect of surging}

The question of how surges interfere with the long-term response of glaciers to climate change has been raised several times (Hagen et al., 2005; Paasche, 2010). Although the present model does not initiate surges by means of an internal mechanism, it does include the main effect of a surge on the surface mass budget of a glacier related to the reduction of the mean surface elevation. Since a lower surface elevation implies a more negative mass budget, one would expect that a regularly surging glacier would have a smaller long-term mean glacier length.

With the present model set-up it is not possible to just switch off the surging mechanism, because by virtue of Eq. (16) the model the glacier would be in the quiescent phase continuously and the ice thickness would increase forever. However, a meaningful way to study the effect of surging is to vary the duration of the surge cycle and see how this effects the long-term mean glacier length. To make a fair comparison between runs with different surge cycles, the constant $C$ in Eq. (16) is adjusted in such a way that the mean value of $S(t)$ is equal to 1 over the integration period.

Figure 10 shows a comparison of runs with a longer (doubled, i.e. 250 years) and shorter (halved, i.e. 62.5 years) surge cycle. The integrations have been extended until AD 3000,

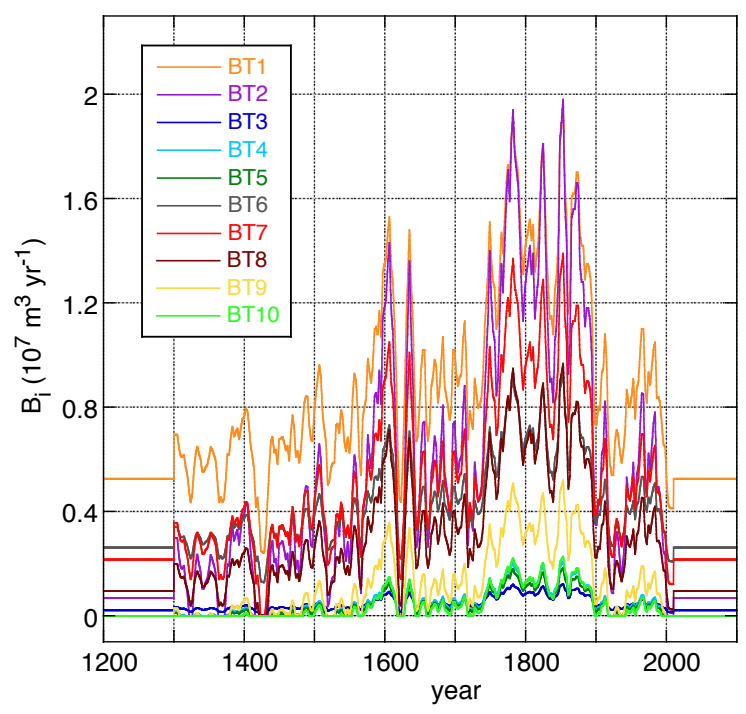

Figure 9. Mass input from the 10 tributary basins and glaciers for the simulation shown in Fig. 8. The location of the basins is shown in Fig. 1.

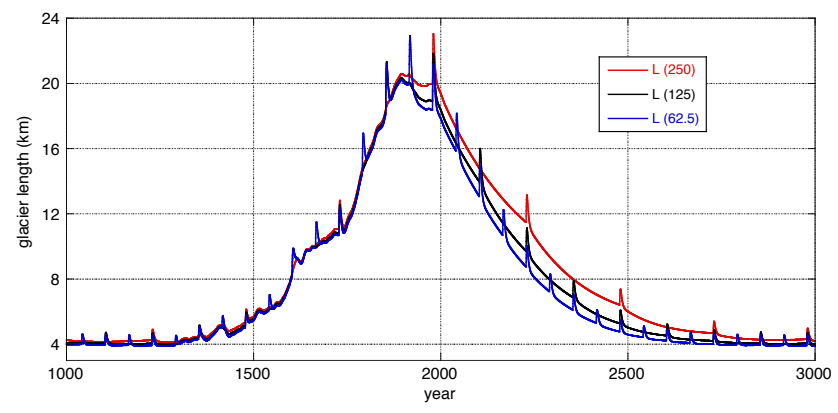

Figure 10. The effect of surges on the evolution of Abrahamsenbreen. The "reference" simulation is the same as in Fig. 8 (note that this simulation has a 125-year surging period).

with the equilibrium-line altitude equal to the mean value over the period 1989-2010. This leads to a steady decay of the glacier, implying that the current size of Abrahamsenbreen is far too large for the climatic conditions that prevailed during the past few decades.

The effect of a different surge frequency is small until AD 1900 but much more obvious afterwards. This is related to the fact that, with a glacier in a state of decay, the massbalance effect of surges works in the same direction as the climatic forcing. Moreover, the glacier surface extends into a region with anomalously high ablation rates. In contrast, for a growing glacier the mass-balance effect of surges works against the climatic imbalance and is therefore less visible.

Many more numerical experiments were carried out with different surge parameters. An increased surge amplitude (larger value of $S_{\mathrm{a}}$ ) enhances the effect on the long-term glacier length because it implies a larger drop of the mean 
surface elevation. When the surge takes longer (larger value of $t_{\mathrm{s}}$ ) there is a similar effect.

The decay of the glacier after the year 2000 is a remarkable feature given the relatively small climatic forcing. In the model simulation, after 1989 the equilibrium line is $76 \mathrm{~m}$ higher than for the period 1300-1989. The new steady state length is about $4 \mathrm{~km}$, but it takes 500 years to approach this state.

The extreme climate sensitivity of Abrahamsenbreen is a consequence of the small bed slope. Basic theory on the relation between $E$ and $L$ for a schematic glacier geometry (constant glacier width) shows that a first-order estimate of the sensitivity is given by (Oerlemans, 2001, 2012)

$\frac{\partial L}{\partial E}=-\frac{2}{\bar{s}}$,

where $\bar{s}$ is the mean bed slope. For the bed parameters used here, a typical value of $\bar{s}$ is 0.015 , implying that $\partial L / \partial E \approx-133$. So a $50 \mathrm{~m}$ change in the equilibrium-line altitude would imply a change in glacier length of $6.7 \mathrm{~km}$. Oerlemans (2011) also reveals that the sensitivity as defined by Eq. (20) is larger when the accumulation zone is wider than the ablation zone. For Abrahamsenbreen this implies that the value of 133 is probably a conservative estimate.

\subsection{Sensitivity to bed elevation}

The basic unknown parameters that can be adjusted to make the model produce the correct glacier length and mean surface elevation are the bed elevation parameter $b_{\mathrm{h}}$, the shape parameter $\alpha_{\mathrm{m}}$ and the reference equilibrium-line altitude $E_{0}$. We thus have three parameters and two constraints, implying that a unique set of parameters cannot be found. In Sect. 5 the problem was solved by assuming that the value of $\alpha_{\mathrm{m}}$ is the same as for Kongsvegen. Although Kongsvegen is also in a post-surge state and is located in a similar geological setting, it is still possible that the value of $\alpha_{\mathrm{m}}$ for Abrahamsenbreen differs significantly. Therefore some calculations were carried out with perturbed values of $\alpha_{\mathrm{m}}$, namely +20 and $-20 \%$.

Changing the value of $\alpha_{\mathrm{m}}$ implies that a recalibration has to be done by adjusting the values of $b_{\mathrm{h}}$ and $E_{0}$ to get the correct glacier length in 1978 and the correct mean surface elevation. For a $20 \%$ larger value of $\alpha_{\mathrm{m}}\left(2.72 \mathrm{~m}^{1 / 2}\right)$ we found $b_{\mathrm{h}}=241 \mathrm{~m}$ (instead of $323 \mathrm{~m}$ ) and $E_{0}=643 \mathrm{~m}$ (instead of $657 \mathrm{~m})$. For a $20 \%$ smaller value of $\alpha_{\mathrm{m}}\left(1.82 \mathrm{~m}^{1 / 2}\right)$ we found $b_{\mathrm{h}}=412 \mathrm{~m}$ and $E_{0}=670 \mathrm{~m}$. Because the ice thickness is proportional to $\alpha_{\mathrm{m}}$, it is not surprising that the adjustments in $b_{\mathrm{h}}$ are quite significant. However, the required changes in the value of $E_{0}$ are rather small.

The evolution of the glacier length for the three different tunings is shown in Fig. 11. It is interesting to see that for the case with $\alpha_{\mathrm{m}}=1.82 \mathrm{~m}^{1 / 2}$ the surge in 1853 produces a slightly longer glacier than in 1978. The differences among the three cases are small for the period of glacier growth and

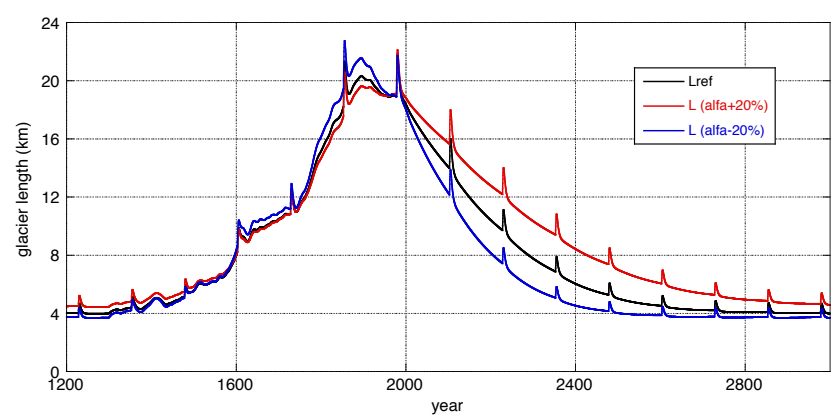

Figure 11. The effect of different values of $\alpha_{\mathrm{m}}$ on the simulated glacier length. The "reference" simulation is shown in red.

significant for the period of glacier retreat after 2000. This is a consequence of the fact that during the period of glacier growth the glacier length was rather close to its equilibrium value most of the time (because, irrespective of short-term fluctuations, the equilibrium line drops gradually). After the year 2000, the glacier is strongly out of balance for the imposed forcing, and the effect of different ice thicknesses on the rate of retreat turns out to be more pronounced.

In summary, we conclude that the simulated glacier evolution depends on the choice of $\alpha_{\mathrm{m}}$ but not in a dramatic way. The characteristic behaviour of Abrahamsenbreen for the imposed forcing is rather similar for the three different tunings.

\subsection{Sensitivity to changes in the equilibrium-line altitude}

By means of numerical modelling it has been shown that a glacier on an isolated mountain bordered by a flat plane will grow to infinity if the equilibrium line is lowered beyond a certain critical value (Oerlemans, 1981; Fig. 10). This occurs because the feedback of the mean surface elevation on the balance rate keeps the total mass budget positive. In the present model the bed profile decays exponentially to a constant value (namely, sea level), and the critical value of the equilibrium-line altitude described above is very likely to be in the system. In the case of Abrahamsenbreen this would imply that for a certain drop of the equilibrium line the glacier would grow and grow until the front reaches the Woodfjord and only mass loss by calving could stabilize the glacier at some point.

Critical (bifurcation) points in a dynamical system normally imply an increasing sensitivity and response time when the critical point is approached. Theoretically, when approaching the critical point the sensitivity and response time go to infinity. The large response time suggested by Fig. 10 actually suggests that Abrahamsenbreen may indeed be close to the critical point. With these considerations in mind we have carried out a set of integrations with different values of $E^{\prime}$ after AD 2010.

Figure 12 shows glacier length for different climatic perturbations, all started with the calibrated glacier history un- 
til AD 2010. Clearly, for $E^{\prime}=-160 \mathrm{~m}$ the glacier quickly comes in a state of runaway growth, and it ultimately grows out of the model domain. For $E^{\prime}=-120 \mathrm{~m}$ the glacier approaches a steady state, albeit very slowly. For further increasing values of $E^{\prime}$, steady states are approached more quickly. In fact, the curves in Fig. 12 show that the response time decreases when the steady-state glacier length is smaller. This is not a direct consequence of the glacier size but is related to the corresponding increase in the mean bed slope and the larger distance (in parameter space) to the critical point.

\subsection{The future of Abrahamsenbreen}

It is very likely that the Arctic will be subject to further warming, which will have a large impact on the glaciers of Svalbard. Reduced sea ice may lead to higher precipitation rates, but it is questionable whether this could stop the retreat of the glaciers. According to Eq. (19), a precipitation increase of about $15 \%$ per degree warming would be required to keep the equilibrium line in place. A detailed analysis of the precipitation regime in the Arctic with a comprehensive climate model suggests a sensitivity of $4.5 \%$ increase per degree of temperature warming (Bintanja and Selten, 2014). Although this is significantly more than the global value of $1.6-1.9 \%$ increase per degree, it is by no means sufficient to prevent the rise of the equilibrium line when temperatures go up.

The future evolution of Abrahamsenbreen can be studied with the present model, because it has been calibrated and no further assumptions are needed to define an initial state. Nevertheless, one should be aware of the schematic nature of the model and the limited data available for Abrahamsenbreen, implying that the constraints are not very tight. The results given below should therefore be considered as indicative of what is a possible scenario rather than a prediction.

We have carried out a set of integrations until AD 2150, with an equilibrium line that rises linearly in time, according to

$E^{\prime}(t)=\mu_{E}(t-2010)$.

Again, the anomaly is defined with respect to the period 1989-2010; time $t$ is in years AD. With the aid of Eq. (19), changes in equilibrium-line altitude can be related to changes in temperature and precipitation. For instance, $\mu_{E}=1 \mathrm{myear}^{-1}$ would correspond to a warming rate of $0.028 \mathrm{Kyear}^{-1}$ or to a warming rate of $0.04 \mathrm{Kyear}^{-1} \mathrm{com}-$ bined with an increase in precipitation of $0.016 \%$ year $^{-1}$. In all the integrations the surge period and amplitude have been kept constant.

Figure 13 shows the result for $\mu_{E}=1 \mathrm{~m}$ year $^{-1}$, which we consider a typical value for the expected warming in the Arctic. In this case the length of Abrahamsenbreen is predicted to be reduced to $12.7 \mathrm{~km}$ by the year 2100 . The corresponding reduction in volume is $66 \%$ of the value in 2010 . The net balance rate for the entire system and the input from the

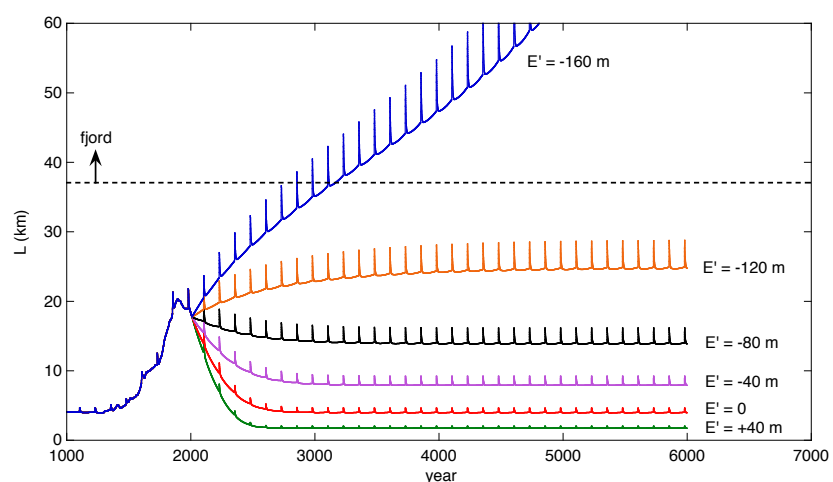

Figure 12. Simulated evolution of Abrahamsenbreen for some selected values of the equilibrium-line altitude (relative to the mean value for the period 1989-2010).

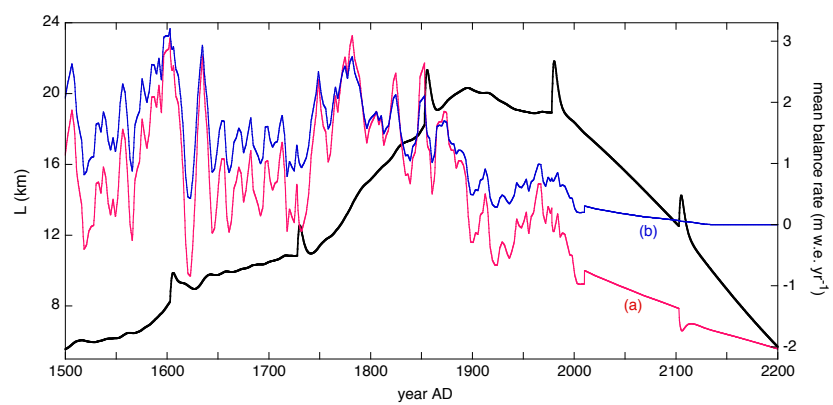

Figure 13. Simulated evolution of Abrahamsenbreen in the case of a rise of the equilibrium line of $1 \mathrm{myear}^{-1}$. Glacier length in black (scale at left). The curve labelled (a) shows the net balance over the entire glacier system; the curve labelled (b) given the mass input from the tributary glaciers, expressed as a mean balance rate.

tributaries is also shown. By the year 2100 the input from the tributary glaciers has been reduced to virtually 0 , because they have a negative net balance.

\section{Discussion}

In this paper we have applied a simple model to study the climate sensitivity of Abrahamsenbreen. We have demonstrated that even with a limited amount of information a meaningful calibration can be carried out, and some conclusions can be drawn about the present state of balance and the future of Abrahamsenbreen under conditions of climate change.

Although the main trunk of Abrahamsenbreen has a relatively simple geometry, the total glacier system is complicated with many basins and tributary glaciers providing mass to the central flow band. The parameterization we have chosen to represent the geometry is effective and contains sufficient information to quantify the overall mass budget. Admittedly, the assumption that the tributaries are in a quasi-steady state is perhaps not always satisfied when the climatic forcing changes rapidly. However, modelling a glacier system 
like Abrahamsenbreen with a two-dimensional (vertically integrated) or three-dimensional ice-flow model, and dealing explicitly with the tributaries would be a complicated task requiring a large amount of input data. We therefore believe that the method used here is suitable to study the dynamics of complex glacier systems with many tributaries.

We found that the effect of surges on the long-term size of the glacier is significant but not dramatic. Since surges are imposed rather than internally generated, only the impact of surges on the mass budget, by lowering of the mean surface elevation, could be dealt with. On the basis of our calculations (Fig. 11), we expect that in a warming Arctic surging glaciers are prone to retreat somewhat faster than non-surging glaciers. It is likely that the effect of surging is larger for glaciers with a larger surge amplitude. However, when comparing the surge amplitude of Abrahamsenbreen with that of some other glaciers in Svalbard (e.g. Skobreen, Kongsvegen, Monacobreen, Nathorstbreen; Sund et al., 2009), it appears that Abrahamsenbreen is quite typical. We therefore think that our results apply to other surging glaciers as well.

It is encouraging that forcing the model with an independently derived climate history leads to a glacier evolution that is in line with the geological and geomorphological evidence. This certainly lends credibility to the approach, and makes projections for the future more believable. If the present climatic conditions persist, we predict that Abrahamsenbreen will shrink considerably (to a length of about $4 \mathrm{~km}$ ). In the case of future warming of a few degree $\mathrm{K}$, the glacier will ultimately disappear, but this will take a few hundred years. Due to the fact that Abrahamsenbreen flows into a valley with a very small bed slope, its sensitivity to climate change is very large. Our calculations suggest that Abrahamsenbreen is rather close to a critical point, marking the onset of a runaway situation in which the glacier will grow into Woodfjorden for only a modest drop of the equilibrium line $(160 \mathrm{~m})$. However, this would take a long time (a few thousand years, Fig. 12).

The large sensitivity of Abrahamsenbreen is probably not an exception. Many large glaciers on Spitsbergen have small slopes and are subject to similar processes. An earlier modelling study of Hansbreen in southern Spitsbergen also revealed a large sensitivity to climate change (Oerlemans et al., 2011). The consequence of these findings is that a temperature increase of $1-2 \mathrm{~K}$ would remove most of the ice from Spitsbergen, although it may take a long time (hundreds to thousands of years). This is in line with the growing evidence for an only marginally glaciated landscape in Spitsbergen during the Holocene Climatic Optimum (e.g. Humlum et al., 2005).
Acknowledgements. Our study was only possible because the Norsk Polarinstitutt does a great job in collecting and issuing maps and photographs through the years. This work was carried out under the programme of the Netherlands Earth System Science Centre (NESSC).

Edited by: A. Vieli

\section{References}

Aðalgeirsdóttir, G., Björnsson, H., Pálsson, F., and Magnússon, E.: Analysis of a surging outlet glacier of Vatnajökull ice cap, Iceland, Ann. Glaciol., 42, 23-28, 2005.

Bintanja, R. and Selten, F. M.: Future increases in Arctic prtecipitation linked to local evaporation and sea-ice retreat, Nature, 509, 479-482, doi:10.1038/nature13259, 2014.

Divine, D., Isaksson, E., Martma, T., Meijer, H., Moore, J., Pohjola, V., van de Wal, R., and Godtliebsen, F.: Thousand years of winter surface air temperature variations in Svalbard and northern Norway reconstructed from ice core data, Polar Res., 30, 7379, doi:10.3402/polar.v30i0.7379, 2011.

Dowdeswell, J. A., Hamilton, G. S., and Hagen, J. O.: The duration of the active phase on surge-type glaciers: contrasts between Svalbard and other regions, J. Glaciol., 37, 388-400, 1991.

Dunse, T., Schuler, T. V., Hagen, J. O., and Reijmer, C. H.: Seasonal speed-up of two outlet glaciers of Austfonna, Svalbard, inferred from continuous GPS measurements, The Cryosphere, 6, 453466, doi:10.5194/tc-6-453-2012, 2012.

Forman, S., Lubinksy, D., Ingólfsson, Ó., Zeeberg, D., Snyder, J. A., and Matishov, G. G.: A review of postglacial emergence on Svalbard, Franz Josef Land and Novaya Zemlya, northern Eurasia, Quaternary Sci. Rev., 22, 1391-1434, 2004.

Fowler, A. C., Murray, T., and Ng, F. S. L.: Thermally controlled glacier surging, J. Glaciol., 42, 527-538, 2001.

Hagen, J. O., Liestøl, O., Roland, E., and Jørgensen, T.: Glacier Atlas of Svalbard and Jan Mayen, Norsk Polarinstitutt, Oslo, Meddelelser Nr. 129, 169 pp., 1993.

Hagen, J. O., Eiken, T., Kohler, J., and Melvold, K.: Geometry changes on Svalbard glaciers: mass-balance or dynamic response?, Ann. Glaciol., 42, 255-261, 2005.

Humlum, O., Elberling, O., Hormes, A., Fjordheim, K., Hansen, O. H., and Heinemeier, J.: Late-Holocene glacier growth in Svalbard, documented by subglacial relict vegetation and living soil microbes, Holocene, 15, 396-407, doi:10.1191/0959683605hl817rp, 2005.

Kamb, B., Raymond, C. F., Harrison, W. D., Engelhardt, H. F., Echelmeyer, K. A., Humphrey, N. F., Brugmann, M. M., and Pfeffer, T.: Glacier surge mechanism, 1982-1983 surge of Variegated Glacier, Alaska, Science, 227, 469-479, 1985.

Mayer, C., Fowler, A. C., Lambrecht, A., and Scharrer, K.: A surge of North Gasherbrum Glacier, Karakorum, China, J. Glaciol., 57, 904-916, 2011.

Melvold, K. and Hagen, J. O.: Evolution of a surge-type glacier in its quiescent phase: Kongsvegen, Spitsbergen, 1964-95, J. Glaciol., 44, 394-404, 1998.

Murray, T., Strozzi, T., Luckman, A., Jiskoot, H., and Christakos, P.: Is there a single surge mechanism? Contrast in dynamics between 
glacier surges in Svalbard and other regions, J. Geophys. Res., 108, 2237, doi:10.1029/2002JB001906, 2003.

Nuth, C., Moholdt, G., Kohler, J., Hagen, J. O., and Kääb, A.: Svalbard glacier elevation changes and contribution to sea level rise, J. Geophys. Res., 115, F01008, doi:10.1029/2008JF001223, 2010.

Oerlemans, J.: Some basic experiments with a vertically-integrated ice-sheet model, Tellus, 33, 1-11, 1981.

Oerlemans, J.: Minimal Glacier Models, 2nd Edn., Igitur, Universiteitsbibliotheek Utrecht, Utrecht, The Netherlands, 103 pp., 2011.

Oerlemans, J.: Linear modeling of glacier fluctuations, Geogr. Ann. A, 94, 183-194, doi:10.1111/j.1468-0459.2012.00469.x, 2012.

Oerlemans, J.: A note on the water budget of temperate glaciers, The Cryosphere, 7, 1557-1564, doi:10.5194/tc-7-1557-2013, 2013.

Oerlemans, J., Jania, J., and Kolondra, L.: Application of a minimal glacier model to Hansbreen, Svalbard, The Cryosphere, 5, 1-11, doi:10.5194/tc-5-1-2011, 2011.

Osipova, G. B. and Tsvetkov, D. G.: Kinematics of the surface of a surging glacier (comparison of the Medvezhiy and Variegated Glacier, IAHS Publ., 208, 345-357, 1991.

Paasche, $\varnothing .:$ Reconstructing climate change: not all glaciers suitable, EOS T. Am. Geophys. Un., 91, 189-190, 2010.

Pohjola, V., Martma, T., Meijer, H., Moore, J., Isaksson, E., Vaikmae, R., and Van De Wal, R.: Reconstruction of three centuries of annual accumulation rates based on the record of stable isotopes of water from Lomonosovfonna, Svalbard, Ann. Glaciol., 35, 57-62, 2002.
Raymond, M. J. and Gudmundsson, G. H.: On the relationship between surface and basal properties in glaciers, ice sheets, and ice streams, J. Geophys. Res., 110, B08411, doi:10.1029/2005JB003681, 2005.

Salvigsen, O. and Høgvard, K.: Glacial History, Holocene shoreline displacement and palaeoclimate based on radiaocarbon ages in the area of Bockfjorden, north-western Spitsbergen, Svalbard, Polar Res., 25, 15-24, 2005.

Sund, M., Eiken, T., Hagen, J. O., and Kääb, A.: Svalbard surge dynamics derived from geometric changes, Ann. Glaciol., 50, 5060, 2009.

Svendsen, J. I. and Mangerud, J.: Holocene glacial and climatic variations on Spitsbergen, Svalbard, Holocene, 7, 45-57, 1997.

van Pelt, W. J. J., Oerlemans, J., Reijmer, C. H., Pohjola, V. A., Pettersson, R., and van Angelen, J. H.: Simulating melt, runoff and refreezing on Nordenskiöldbreen, Svalbard, using a coupled snow and energy balance model, The Cryosphere, 6, 641-659, doi:10.5194/tc-6-641-2012, 2012.

van Pelt, W. J. J., Oerlemans, J., Reijmer, C. H., Pettersson, R., Pohjola, V. A., Isaksson, E., and Divine, D.: An iterative inverse method to estimate basal topography and initialize ice flow models, The Cryosphere, 7, 987-1006, doi:10.5194/tc-7-987-2013, 2013.

Vialov, S. S.: Regularities of glacial shields movement and the theory of plastic viscous flow, Int. Assoc. Hydro. Sci. Pub., 47, 266275, 1958.

Weertman, J.: Stability of ice-age ice sheets, J. Geophys. Res., 66, 3783-3792, 1961 